\title{
STRESS CONCENTRATION RESULTING FROM IRREGULAR SHAPE OF EXPLOSIVELY CLADDED MATERIALS CONNECTIONS - FEM SIMULATION
}

\author{
Andrzej KUREK*, Adam NIESŁONY*, Marta KUREK* \\ *Faculty of Mechanical Engineering, Department of Mechanics and Machines Design, Opole University of Technology, \\ ul. Mikołajczyka 5, 45-271 Opole, Poland \\ a.kurek@po.opole.pl, a.nieslony@po.opole.pl, ma.kurek@po.opole.pl
}

\begin{abstract}
The paper contains a numerical analysis of interface zone steel-titanium bimetal obtained by explosive cladding method. Due to the waviness of the zone, and various properties of the constituent material of the materials type contain structural notch. Therefore it is important inter alia in terms of presentation of the results of fatigue are the maximum stresses that occur just in the area of the zone. In the paper the stress concentration factor and the proposed method of modelling the joint zone of a sinusoidal profile, characterized by the same coefficient of stress concentration at the actual profile.
\end{abstract}

Keywords: FEM, Explosive Cladding, Interference Zone

\section{INTRODUCTION}

Energy of explosion has been applied for peaceful aims for a long time. Explosive materials can be applied for mineral crushing, demolition of buildings, fire suppression (blowing the flame away), stretching the belts and filling the airbags, shooting rackets or rescue cartridges, treatment of metallic and nonmetallic materials (pressure welding, hardening, pressing, forming, generation of phase changes). Intense energy released in a short time while explosion gives a possibility of realization of technological processes which could not be realized in typical conditions. The mentioned technologies using the explosion force have one common feature - suitable application of extreme values of velocity and pressure accompanying the explosion.

Explosive cladding allows joining materials with completely different properties which are difficult to obtain by means of other methods of joining (Niesłony et al., 2010). Clad obtained with this method are materials of strongly gradient properties and they have complex joining zones (Čížek et al., 2010, Karolczuk et al., 2013, Wronka, 2010, 2011). Materials obtained by this method can also be affected by mean stresses, which can influence the results of fatigue tests, more about this problem can be found in Lindemann and Wagner (1997).

The clad materials are often applied in processing apparatus (chemical and power industries). Wide application of titanium and its alloys in power engineering (condensers, steam condensers, heat exchangers and steam turbines in power plants and thermalelectric power stations) causes that the problem of fatigue life of bimetallic clads, for example, those of steel-titanium type, becomes more and more important (Jiang et al., 2014]). As for many applications, fatigue life of clads is the most important parameter. Taking the specify of the problem into account, the tests are performed according to suitable standards, but the tests not included into the standards are also realized (Sun, 2013; Zareie Rajani $H R, 2013)$. The strength tests presented in this paper concern the metallic composite, so-called clad, obtained during so-called explosive cladding (Findik, 2011; Szulc et al., 2007). This paper is a continuation of the previous papers concerning strength of clad materials (Kurek and Niesłony, 2012), and special attention is paid to fatigue life of such materials. To address this problem, a numerical analysis of the interference zone of this bimetal, using FEM was performed. A similar approach, but for welded joints, was presented by Dong (2001).

An example of explosively cladded interference zone is shown in Fig. 1.

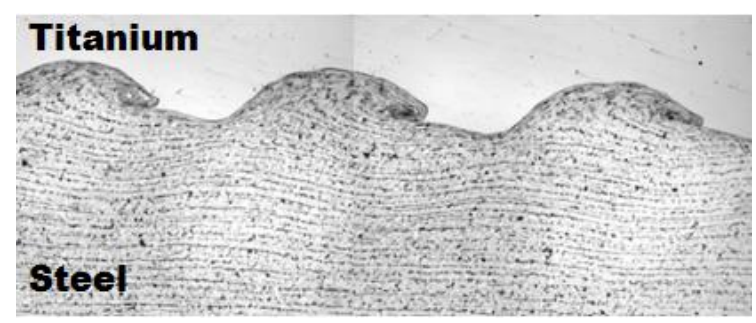

Fig. 1. Example of interference zone of explosively cladded steel-titanium

\section{SIMULATION}

When modeling the interface zone COMSOL Multiphysics 3.5 environment was used fo finite element method calculations. Due to the lack of exfoliation and high resistance to static tearing the interface was modeled as an integral and inseparable. Because of possible melting areas, in which on the basis of metallographic studies intermetalics and non-metallic inclusions were noted (Król et al., 2007), were not concidered the calculation assumes two homogeneous metal zones: titanium ( $E=105 \mathrm{GPa}, v=0.33$ ) and steel $(E=203 \mathrm{GPa}, v=0.33)$.

The profile of the bimetal interface was modeled in three ways:

1. as a straight line,

2. aligning it using sine function, and

3. the representation of the shape of the actual connections based on microscopic images of the selected portion of the bimetal. 
In mode 1) and 3) the transition between metallic zones of titanium and steel was defined to in a geometric manner with the line. In mode 2) a change in the material properties while FEM caclulations was defined by the logical function that allowed rapid change of amplitude and period of the sine function defining the transition lines represented by formula (1).

$E=\left\{\begin{array}{lll}E_{1} & \text { dla } & y_{1}>\left(y-y_{2} \cdot \sin \left(\frac{x \cdot \pi}{x_{1}}\right)\right) \\ E_{2} & \text { dla } & y_{1} \leq\left(y-y_{2} \cdot \sin \left(\frac{x \cdot \pi}{x_{1}}\right)\right)\end{array}\right.$, where: $E_{1}, E_{2}$ - Young's modules of particular materials, $x, y$ - coordinates of the FEM model, $x_{1}$ - wavelength ratio, $y_{1}$ - coordinates of the modeled sample middle, $y_{2}$ - wave height.

In this case also and adaptive generation of FEM mesh was used, which is based on the following grid congestions around the big changes (gradient method).
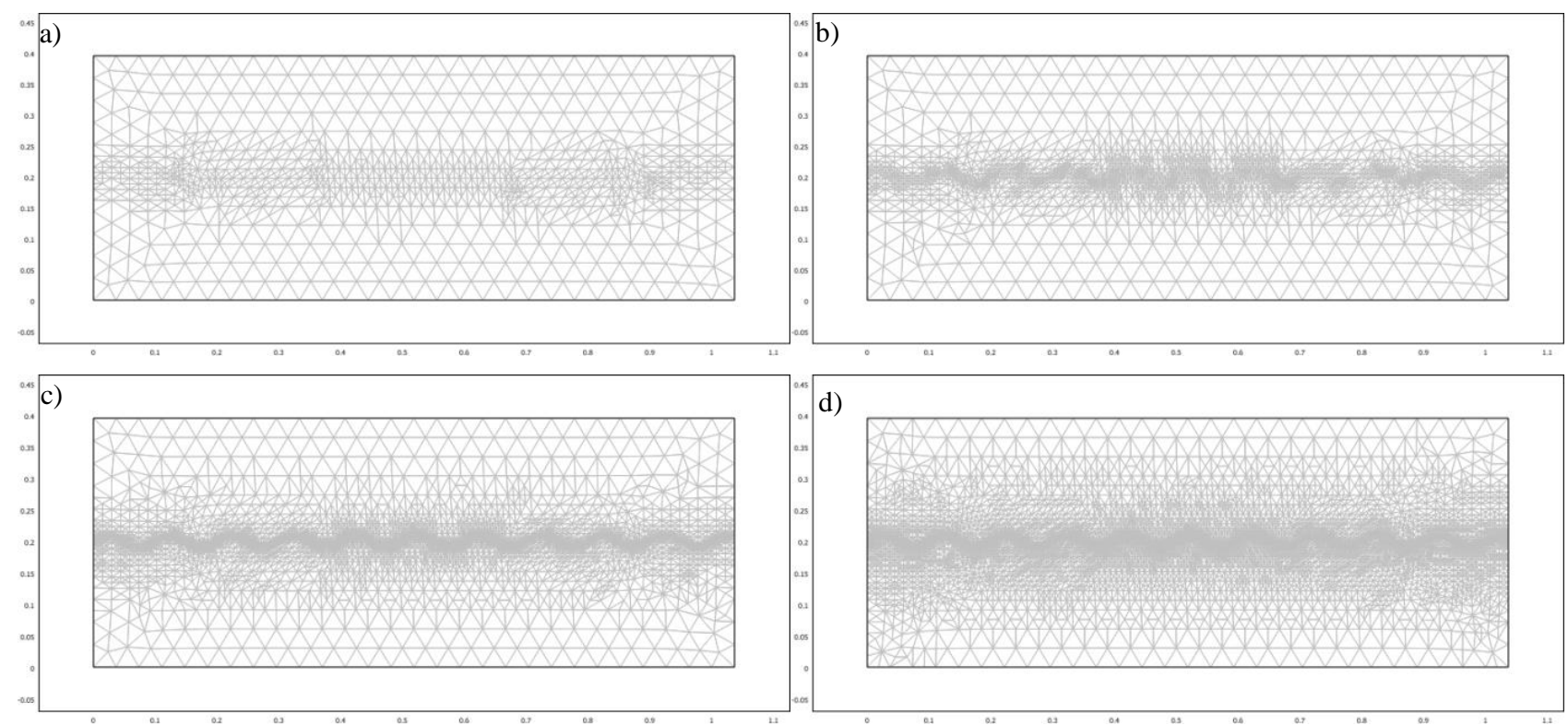

Fig. 2. Steps of FEM mesh compaction by an adaptive method

A model of the interface real shape was obtained by performing a micrograph of the sample used for fatigue test as shown in Fig. 3.

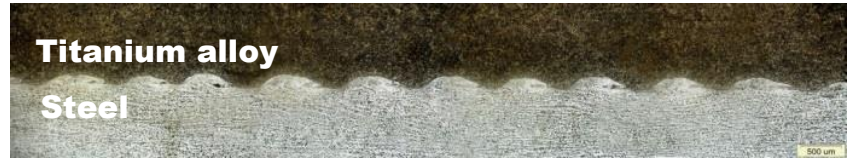

Fig. 3. Real interference zone for titanium-steel bimetal usted for simulations

Due to the lack of information on possible changes in the shape of the interference zone in the direction perpendicular to the microsection spatial joint modeling was abandoned. This limitation allowed for the execution of the plane model. Element was stretched along the interference line by causing maximum displacement on the right edge of the model equal to the length of the sample times 0.001 .

In this way, values of stresses induced in material corresponds with the 0.001 of the Young's modulus for constituent materials in areas without affecting the structural notch.

Fig. 4 shows the results of a calculation model with interference profile obtained on the basis of the actual shape of the wave. Fig. $4 a$. shows the areas of the stress values equal to 220 $\mathrm{MPa}$ and $110 \mathrm{MPa}$ for steel and titanium respectively. Fig. 5 shows courses of reduced stresses acording to Huber-Mises hypothesis (a) and shear stress $\tau_{x y}(b)$ for the six cross-sections taken at the FEM model correspond to the locations marked with numbers from 1 to 6 in Fig. 4.

The next stage of the study was to find a replacement shape for real interference formed as a result of explosive welding (cladding), easy to use but and at the same time able to preserves the characteristics of the real shape. Natural candidate seemed trigonometric sine function.

So an attempt to simulate was taken, shape was obtained by assigning, with the help of the sine function, various Young's modules values to two different materials material - titanium and steel, see eq. (1). Parts above of the waveform of sine function placed in the middle height of the specimen was assigned SB265G1 properties of titanium, while below the properties of the steel S355J2. FEM mesh modeling was performed in COMSOL environment by using adaptive mesh thickening function, which thickens grid mainly in the area of large stress gradients.

The parameters are chosen in such a way that the size of the components is comparable with the earlier model with interference actual shape and size (Fig. 3). Sine function modeled in such a way that the height and length of the wave correspond to the actual dimensions of the images obtained from the microsection shown in Fig. 3. Fig. 7 shows courses of Huber-Mises stress and shear stress for sinusoidal shape steel-titanium connection corresponding to the locations indicated in Fig. 1-6, figs. 6a and $6 b$. 

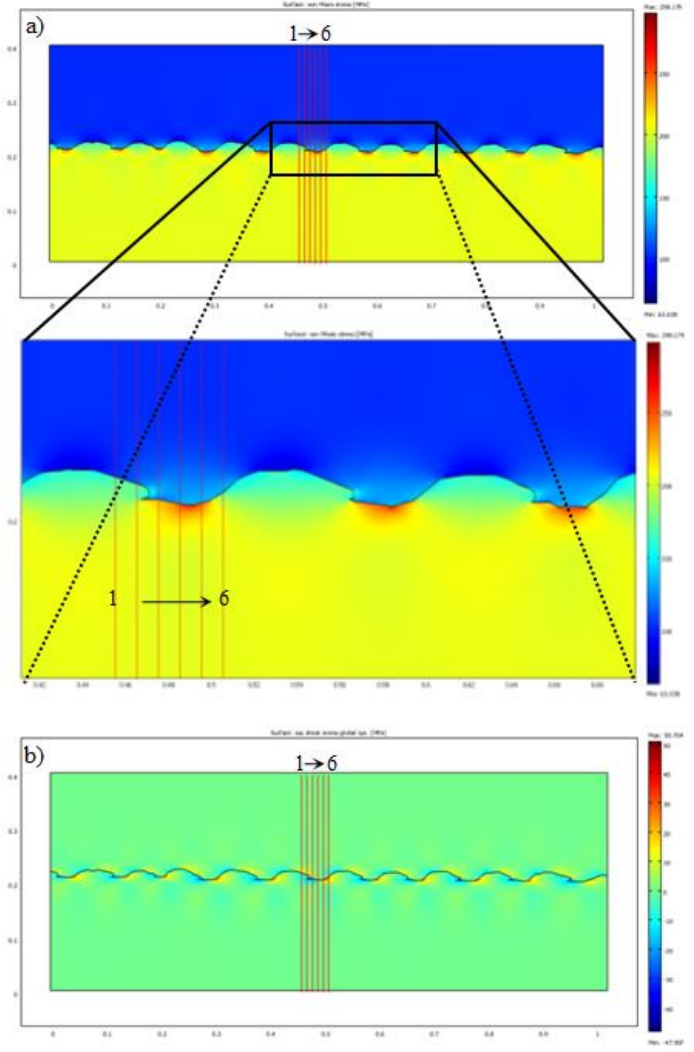

Fig. 4. FEM stress analysis of actual titanium-steel interference in tension, respectively: a) Huber-Mises stresses, b) shear stress
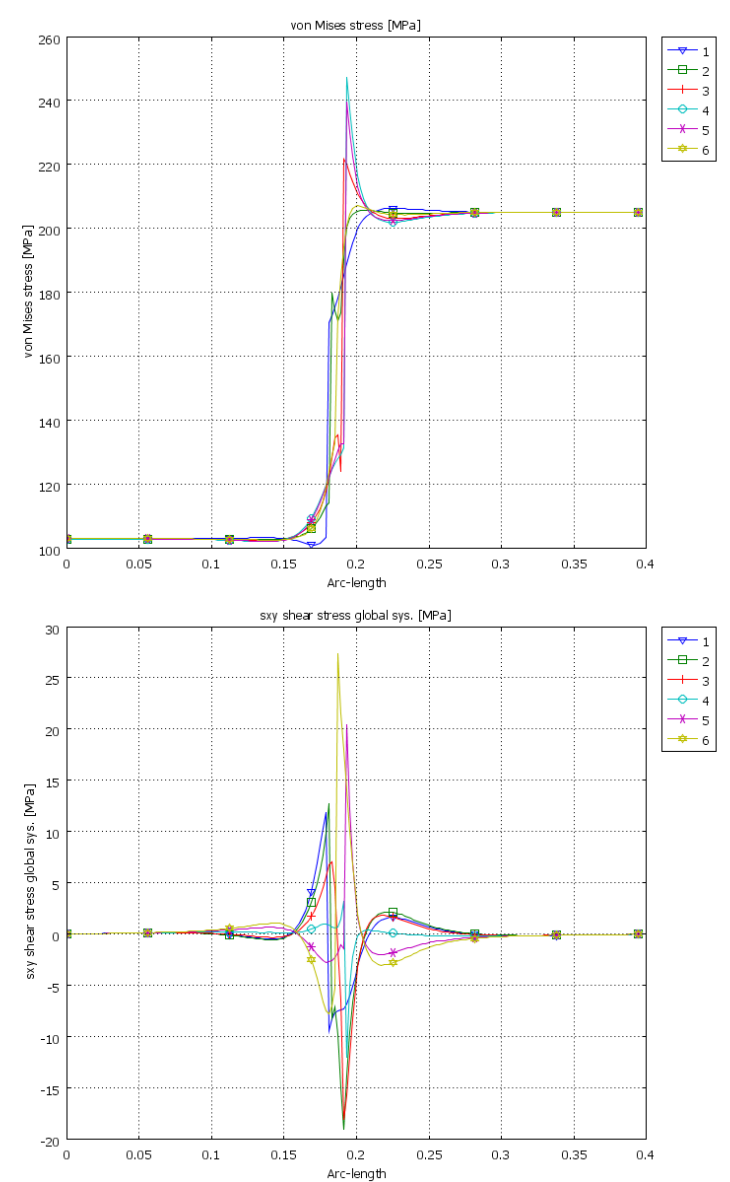

Fig. 5. Courses of streesses for actual steel-titanium interference in six sections marked on Fig. 4, respectively:

a) Huber-Mises stresses, b) shear stress
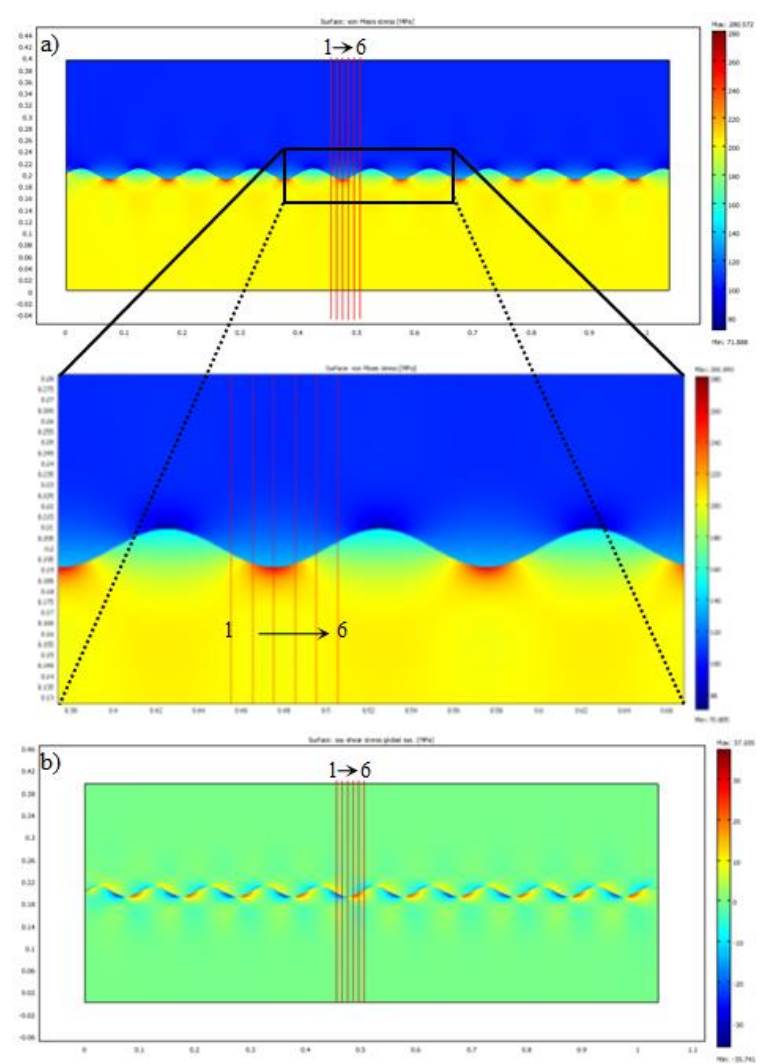

Fig. 6. FEM stress analysis of titanium-steel interference simulated by the sin function, respectively: a) Huber-Mises stresses, b) shear stress
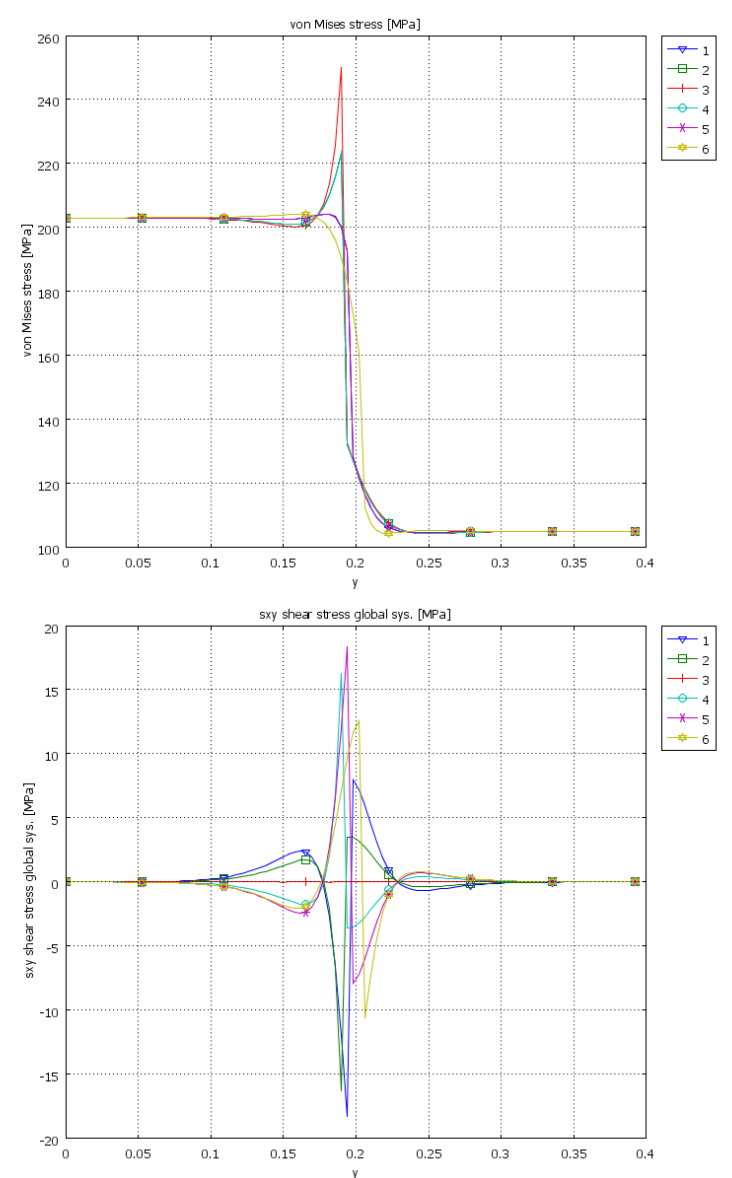

Fig. 7. Courses of streesses for steel-titanium interference simulated by sin function in six sections marked on Fig. 6, respectively: a) Huber-Mises stresses, b) shear stress 


\section{CONCLUSIONS AND OBSERVATIONS}

After the simulation calculations we noticed that the replacement of the actual waveform of explosively cladded material connection with sine function with corresponding wavelength and wavehigh leads to a close results of reduced stress Huber-Mises in the bottom of the wave. Comparison of Figs. $5 a$ and $7 a$ conclusions can be drawn that the stress distribution around the connectors are similar and there is no need for additional scaling of the sine function. A difference in the maximum stress occurring in the models was also noted, however, this state of affairs can be explained by the difficulty in accurate mapping of the actual waveform, and arising out of the grounds in places with very sharp changes in shape that cause stress concentrations, which are in fact more benign. Stresses in the same area index merger wave in both models, however, are very similar and are up to about 250 $\mathrm{MPa}$ for the test case. While in the case of shear stress for connection modeled by the sine fucnction a decrease in the values was noted for both the maximum stress shown on Figure $4 b$ and $6 b$ as on $5 b$ and $7 b$ corresponding to the courses of stress in transverse sections. Such a situation can also be explained by a more regular sinusoidal waveform. The difference in the values of these stresses is not large and is about $9 \mathrm{MPa}$ in the case of stress in transverse sections for Figs. $5 \mathrm{~b}$ and $7 \mathrm{~b}$.

\section{REFERENCES}

1. Čižek L., Ostroushko D., Szulc Z. (2010), Properties of Sandwich Metals Joined by Explosive Cladding Method, Archives of Materials Science and Engineering, Vol. 43, 21-29.

2. Dong P. (2001), A structural stress definition and Numerical Implementation for Fatigue Analysis of Welded Joints, International Journal of Fatigue,23, 865-876.

3. Findik F., (2011), Recent Developments in Explosive Welding, Materials \& Design, 32, 1081-1093.

4. Jiang H., Yan X., Liu J., Duan X. (2014), Effect of Heat Treatment on Microstructure and Mechanical Property of Ti-Steel ExplosiveRolling Clad Plate, Transactions of Nonferrous Metals Society of China, 24, 697-704.
5. Karolczuk A., Kowalski M., Bański R., Żok F. (2013), Fatigue Phenomena in Explosively Welded Steel-Titanium Clad Components Subjected to Push-Pull Loading, International Journal of Fatigue 48, 101-108.

6. Król S., Bański R., Szulc Z., Gałka A. (2007), Practical Aspects of Structural Tests of Titanium-Steel Bonds Made by Explosive Cladding and Exposed to Thermal Process Loads, Advences in Material Science, vol. 7, nr 4(14), 50-56.

7. Kurek A., Niesłony A. (2012), Fatigue Life Tests of Explosively Cladded Steel-Titanium Bimetal, Materials Science Forum, Vol. 726, 106-109.

8. Lindemann J., Wagner L. (1997), Mean stress sensitivity in Fatigue Of $\alpha,(\alpha \beta)$ and $\beta$ Titanium Alloys, Materials Science and Engineering, 234-236, 1118-1121.

9. Niesłony A., Kurek A., Bański R., Čižek L. (2010), Static and fatigue tests of explosively cladded materials - titanium-steel, Scientific Papers Opole University of Technology, Series Mechanics, 97, 337/2010 (in Polish).

10. Sun T., Liang J., Guo X., Li L. (2013), Tensile Anisotropy of Cu/Al Clad Metals After Prestrain Using Digital Image Correlation, Journal of Materials Engineering and Performance, 22, 3825-3833.

11. Szulc Z., Gałka A., Bański R., Pocica A. (2007), Explosive Cladding With Titanium - the development of technologies and Areas of Industrial Applications, XII Scientific and Technical Welding Conference "Progress, innovation and Quality Requirements of Welding Processes", 13-14 (in Polish).

12. Wronka B. (2010), Testing of Explosive Welding and Welded Joints: Joint Mechanism and Properties of Explosive Welded Joints, J Mater Sci, 45, 4078-4083.

13. Wronka B. (2011), Testing of Explosive Welding and Welded Joints. Wavy Character of the Process and Joint Quality, International Journal of Impact Engineering, 38, 309-313. 3

14. Zareie Rajani HR., Akbari Mousavi SAA., Madani Sani F. (2013), Comparison of Corrosion Behavior between Fusion Cladded and Explosive Cladded Inconel 625/Plain Carbon Steel Bimetal Plates, Materials \& Design, 43, 467-474.

The Project was financed from a Grant by National Science Centre (Decision No. DEC-2012/05/B/S T8/02520). 